Military Technical College

Kobry El-Kobbah,

Cairo, Egypt

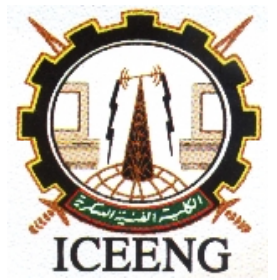

\section{$8^{\text {th }}$ International Conference on Electrical Engineering ICEENG 2012}

\title{
Dynamic Economic Load Dispatch of Thermal Power System Using Particle Swarm Optimization Technique
}

\author{
W.M. MANSOUR* M.M. SALAMA* S.M. ABDELMAKSOUD ** H.A. HENRY*** \\ Department of Electrical Engineering, Faculty of Engineering (Shoubra), \\ Benha University, Cairo, Egypt.
}

\begin{abstract}
Economic load dispatch (ELD) problem is one of the most important problems to be solved in the operation and planning of a power system. The main objective of the ELD problem is to determine the optimal schedule of output powers of all generating units so as to meet the required load demand at minimum operating cost while satisfying system equality and inequality constraints. This paper presents a new approach using Particle Swarm Optimization (PSO) for solving the ELD problem with considering the generator constraints, ramp rate limits and transmission line losses. The proposed approach has been evaluated on 26-bus, 6unit system. The obtained results of the proposed method are compared with those obtained from the conventional lambda iteration method. The results show that the proposed approach is feasible and efficient.
\end{abstract}

\section{Keywords:}

Economic load dispatch, Particle swarm optimization, Ramp rate limits. and system equality and inequality constraints [1].

\footnotetext{
* Professor of Electrical Power Systems, ** Assistant Professor of Electrical Engineering, *** Demonstrator of Electrical Engineering,
} 


\section{Introduction}

With the development of modern power systems, economic load dispatch (ELD) problem has received an increasing attention. The primary objective of ELD problem is to minimize the total generation cost of units while satisfying all units In this problem, the generation costs are represented as curves and the overall calculation minimizes the operating cost by finding the point where the total output power of the generators equals the total power that must be delivered. In the traditional ELD problem, the cost function for each generator has been represented approximately by a single quadratic function and is solved using mathematical programming based optimization techniques such as lambda iteration method, gradient method, Newton method, linear and dynamic programming methods [2,3]. All these methods assume that the cost curve is continuous and monotonically increasing. In these methods, computational time increases with the increase of the dimensionality of the ELD problem. The most common optimization techniques based upon artificial intelligence concepts such as evolutionary programming [4], simulated annealing , artificial neural networks [5], genetic algorithm [6,7], tabu search [8] and particle swarm optimization (PSO) [9-12] have been given attention by many researchers due to their ability to find an almost global optimal solution for ELD problems with operating constraints. Major problem associated with these techniques is that appropriate control parameters are required. Some times these techniques take large computational time due to improper selection of the control parameters. The PSO is a population based optimization technique first proposed by Kennedy and Eberhart in 1995. In PSO, each particle is a candidate solution to the problem. Each particle in PSO makes its decision based on its own experience together with other particles experiences. Particles approach to the optimum solution through its present velocity, previous experience and the best experience of its neighbors [13]. Compared to other evolutionary computation techniques, PSO can solve the problems quickly with high quality solution and stable convergence characteristic, whereas it is easily implemented.

\section{Formulation of an ELD with Generator Constraints}


The primary objective of the ELD problem is to minimize the total fuel cost of thermal power plants subjected to the operating constraints of a power system. In general, the ELD problem can be formulated mathematically as a constrained optimization problem with an objective function of the form:

$$
F_{T}=\sum_{i=1}^{n} F_{i}\left(P_{i}\right)
$$

where $F_{T}$ is the total fuel cost of the system, $\mathrm{n}$ is the total number of generating units and $F_{i}\left(P_{i}\right)$ is the operating fuel cost of generating unit $\mathrm{i}$.

Generally, the fuel cost function of the generating unit is expressed as a quadratic function as given in (2)

$$
F_{i}\left(P_{i}\right)=a_{i} P_{i}^{2}+b_{i} P_{i}+c_{i}
$$

where $P_{i}$ is the real output power of unit $\mathrm{i} ; a_{i}, b_{i}$ and $c_{i}$ are the cost coefficients constants of generating unit $\mathrm{i}$.

The minimization of the ELD problem is subjected to the following constraints:

I) Real Power Balance Constraint:

For power balance, an equality constraint should be satisfied. The total generated power should be equal to the total load demand plus the total losses. The active power balance is given by

$$
\sum_{i=1}^{n} P_{i}=P_{D}+P_{L}
$$

Where, $P_{D}$ is the total load demand $(\mathrm{MW}), P_{L}$ represents the total line losses (MW). The total transmission line loss is assumed as a quadratic function of output powers of the generator units [14] that can be approximated in the form:

$$
P_{L}=\sum_{i=1}^{n} \sum_{j=1}^{n} P_{i} \mathrm{~B}_{i j} P_{j}
$$

Where $\mathrm{B} i_{j}$ is the transmission line loss coefficient, $P_{i}$ and $P_{j}$ are the power generation of $i^{\text {th }}$ and $j^{\text {th }}$ units.

II) Generator Power Limit Constraint: 
The generation output power of each unit should lie between minimum and maximum limits. The inequality constraint for each generator can be expressed as:

$$
P_{i, \min } \leq P_{i} \leq P_{i, \max }
$$

Where $P_{i, \text { min }}$ and $P_{i, \max }$ are the minimum and maximum power outputs of generator i (MW), respectively. The maximum output power of generator is limited by thermal consideration and minimum power generation is limited by the flame instability of a boiler.

III) Ramp Rate Limit Constraint:

The generator constraints due to ramp rate limits of generating units are given as:

a) as generation increases:

$$
P_{i(t)}-P_{i(t-1)} \leq U R_{i}
$$

b) as generation decreases:

$$
P_{i(t-1)}-P_{i(t)} \leq D R_{i}
$$

Therefore the generator power limit constraints can be modified as:

$$
\max \left(P_{i, \min }, P_{i(t-1)}-D R_{i}\right) \leq P_{i(t)} \leq \min \left(P_{i, \max }, P_{i(t-1)}+U R_{i}\right)
$$

where $P_{i(t)}$ is the output power of generating unit $\mathrm{i}(\mathrm{MW})$ in the time interval (t), $P_{i(t-1)}$ is the output power of generating unit $\mathrm{i}(\mathrm{MW})$ in the previous time interval $(\mathrm{t}-1), U R_{i}$ is the up ramp limit of generating unit $\mathrm{i}$ (MW/time-period) and $D R_{i}$ is the down ramp limit of generating unit i (MW/time-period).

The ramp rate limits of the generating units with all possible cases are shown in Fig.1.
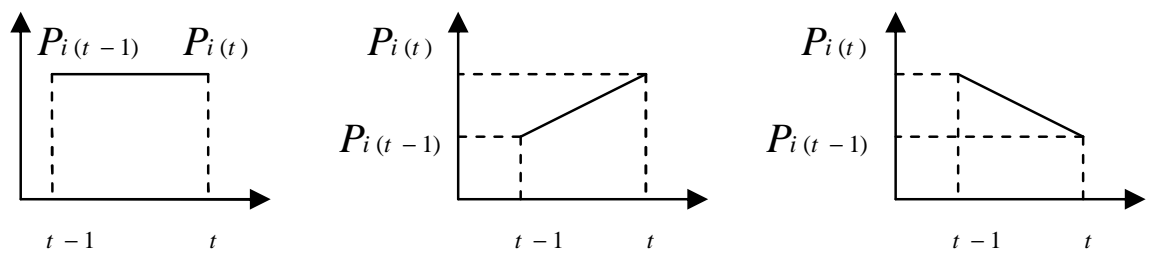

Fig.1. Ramp rate limits of the generating units.

\section{Overview of the Lambda Iteration Method}


The formulation of Lagrange function for the ELD problem is given by:

$$
F=F_{T}+\lambda\left(P_{D}+P_{L}-\sum_{i=1}^{n} P_{i}\right)
$$

The condition for optimal operation can be obtained by differentiating $F$ with respect to $P_{i}$ as follows:

$$
\frac{d F_{i}}{d P_{i}}+\lambda \frac{\partial P_{L}}{\partial P_{i}}=\lambda
$$

The coordination equation can be given as:

$$
f_{i i} P_{i}+f_{i}+\lambda \sum_{i} 2 \mathrm{~B}_{i j} P_{i}=\lambda
$$

The expression for output power is:

$$
P_{i}=\frac{1-\frac{f_{i}}{\lambda}-\sum_{i \neq j} 2 \mathrm{~B}_{i j} P_{i}}{\frac{f_{i i}}{\lambda}+2 \mathrm{~B}_{i i}}
$$

The step by step algorithm for the Lambda Iteration method is explained as follow:

Step 1: Assume a suitable value of $\lambda^{(0)}$ which has more than the largest value of $f_{i}$ (intercept of the incremental cost of various generators)

Step 2: Calculate the generations based on equal incremental production cost.

Step 3: Calculate generations at all buses $\left(P_{1}, P_{2}, P_{3}, \ldots \ldots . ., P_{i}\right)$ from equation (12).

Step 4: Check the equality and inequality constraints.

Step 5: Check if the difference in power at all generator buses between two successive iterations is less than a pre specified value $(\varepsilon)$, if not go back to step 3 .

Step 6: Calculate transmission line losses from equation (4).

Step 7: Calculate $|\Delta P|=\left|\sum_{i=1}^{n} P_{i}-P_{L}-P_{D}\right|$ 
If $|\Delta P| \leq \varepsilon$ ( $\varepsilon$ is the tolerance), calculate the cost of generation and the values of power for all units and then go to step 8. If $|\Delta P|>\varepsilon$, update the value of $\lambda$ and go back to step 3 .

Step 8: Stop

\section{Particle Swarm Optimization (PSO)}

Particle swarm optimization (PSO) is a population based stochastic optimization technique, inspired by social behavior of bird flocking or fish schooling. It is one of the most modern heuristic algorithms, which can be used to solve non linear and non continuous optimization problems. PSO shares many similarities with evolutionary computation techniques such as genetic algorithm (GA). The system is initialized with a population of random solutions and searches for optima by updating generations. However, unlike GA, PSO has no evolution operators such as mutation and crossover. The PSO algorithm searches in parallel using a group of random particles. Each particle in a swarm corresponds to a candidate solution to the problem. Particles in a swarm approach to the optimum solution through its present velocity, its previous experience and the experience of its neighbors. In every generation, each particle in a swarm is updated by two best values. The first one is the best solution (best fitness) it has achieved so far. This value is called Pbest. Another best value that is tracked by the particle swarm optimizer is the best value, obtained so far by any particle in the population. This best value is a global best and called gbest. Each particle moves its position in the search space and updates its velocity according to its own flying experience and neighbor's flying experience. After finding the two best values, the particle update its velocity according to equation (13).

$V_{i}{ }^{k+1}=\omega \times V_{i}{ }^{k}+C_{1} \times R_{1} \times\left(\right.$ Pbest $\left._{i}{ }^{k}-P_{i}{ }^{k}\right)+C_{2} \times R_{2} \times\left(\right.$ gbest $\left.^{k}-P_{i}{ }^{k}\right)$

Where $V_{i}{ }^{k}$ is the velocity of particle $\mathrm{i}$ at iteration $\mathrm{k}, P_{i}{ }^{k}$ is the position of particle $\mathrm{i}$ at iteration $\mathrm{k}, \omega$ is the inertia weight factor, $C_{1}$ and $C_{2}$ are the acceleration coefficients, $R_{1}$ and $R_{2}$ are positive random numbers between 0 and 1, Pbest $^{k}{ }^{k}$ is the best position of particle $\mathrm{i}$ at iteration $\mathrm{k}$ and gbest $^{k}$ is the best position of the group at iteration $\mathrm{k}$. 
In the velocity updating process, the acceleration constants $C_{1}, C_{2}$ and the inertia weight factor are predefined and the random numbers $R_{1}$ and $R_{2}$ are uniformly distributed in the range of $[0,1]$. Suitable selection of inertia weight in equation (13) provides a balance between local and global searches. Thus requiring less iteration on average to find a sufficiently optimal solution. A low value of inertia weight implies a local search, while a high value leads to global search. As originally developed, the inertia weight factor often decreases often is decreased linearly from about 0.9 to 0.4 during a run. It was proposed in [15]. In general, the inertia weight $\omega$ is set according to equation (14)

$\omega=\omega_{\max }-\frac{\omega_{\max }-\omega_{\min }}{\text { Iter } \max } \times$ Iter

Where $\omega_{\min }$ and $\omega_{\max }$ are the minimum and maximum value of inertia weight factor, Iter $\max$ corresponds to the maximum iteration number and Iter is the current iteration number.

The current position (searching point in the solution space) can be modified by equation (15)

$$
P_{i}^{k+1}=P_{i}^{k}+V_{i}^{k+1}
$$

The velocity of particle $\mathrm{i}$ at iteration $\mathrm{k}$ must lie in the range:

$V_{i \min } \leq V_{i}^{k} \leq V_{i \max }$

The parameter $V_{\max }$ determines the resolution or fitness, with which regions are to be searched between the present position and the target position. If $V_{\max }$ is too high, the PSO facilitates a global search and particles may fly past good solutions. Conversely, if $V_{\max }$ is too small, the PSO facilitates a local search and particles may not explore sufficiently beyond locally good solutions. In many experiences with PSO, $V_{\max }$ was often set at $10-20 \%$ of the dynamic range on each dimension.

The constants $C_{1}$ and $C_{2}$ represent the weighting of the stochastic acceleration terms that pull each particle toward Pbest and gbest positions. Low values allow particles to roam far from the target regions, while high values result in abrupt movement toward, or past, target regions. Hence, the acceleration constants were often set to be 2.0 according to past experiences. 


\section{Implementation of PSO for Solving ELD Problem}

A step by step procedure of the proposed PSO method for solving ELD problem is as follows:

Step 1: Select the parameters of PSO such as population size $(\mathrm{N})$, acceleration constants $\left(C_{1}\right.$ and $\left.C_{2}\right)$, minimum and maximum value of inertia weight factor $\left(\omega_{\min }\right.$ and $\left.\omega_{\max }\right)$.

Step 2: Initialize a population of particles with random positions and velocities. These initial particles must be feasible candidate solutions that satisfy the practical operation constraints.

Step 3: Evaluate the fitness value of each particle in the population using the objective function given in equation (2).

Step 4: Compare each particle's fitness with the particles Pbest. If the current value is better than Pbest, then set Pbest equal to the current value.

Step 5: Compare the fitness with the population overall previous best. If the current value is better than gbest, then set gbest equal to the current value.

Step 6: Update the velocity of each particle according to equation (13).

Step 7: The position of each particle is modified using equation (15).

Step 8: Go to step 9 if the stopping criteria is satisfied, usually a sufficiently good fitness or a maximum number of iterations. Otherwise go to step 3.

Step 9: The particle that generate the latest gbest is the optimal generation power of each unit with the minimum total cost of generation.

\section{Case Study and Simulation Results}

To verify the effectiveness of the proposed particle swarm optimization (PSO) algorithm, a six unit thermal power generating plant was tested. The proposed algorithm has been implemented in MATLAB language. The proposed algorithm is applied to 26 buses, 6 generating units with generator constraints, ramp rate limits and transmission losses [16]. The results obtained from the proposed PSO method will be compared with the outcomes obtained from the conventional 
lambda iteration method in terms of the solution quality and computation efficiency. The fuel cost data and ramp rate limits of the six thermal generating units were given in Table 1. The load demand for 24 hours is given in Table 2. Bloss coefficients of six units system is given in Equation (17). Output powers, power loss and total fuel cost obtained by the lambda iteration method for 24 hours are given in Table 3. Output powers, power loss and total fuel cost obtained by the proposed PSO method for all power demands are given in Table 4. Figures (2-7) show the relation between fuel cost of each unit and 24 hours by the two used methods.

Some parameters must be assigned for the use of PSO algorithm to solve ELD problems as follows:

- $\quad$ Population size $=20$

- Maximum number of iterations $=120$

- Acceleration constants $C_{1}=2.0$ and $C_{2}=2.0$

- Inertia weight parameters $\omega_{\max }=0.9$ and $\omega_{\min }=0.4$

Table 1: Fuel cost coefficients and ramp rate limits of six thermal units system

\begin{tabular}{|c|c|c|c|c|c|c|c|}
\hline Unit & $\mathrm{a}_{\mathrm{i}}$ & $\mathrm{b}_{\mathrm{i}}$ & $\mathrm{c}_{\mathrm{i}}$ & $\mathrm{P}_{\mathrm{i}, \min }$ & $\mathrm{P}_{\mathrm{i}, \max }$ & $\mathrm{UR}_{\mathrm{i}}$ & $\mathrm{DR}_{\mathrm{i}}$ \\
$\left(\$ / \mathrm{MW}^{2}\right)$ & $(\$ / \mathrm{MW})$ & $(\$)$ & $(\mathrm{MW})$ & $(\mathrm{MW})$ & $(\mathrm{MW} / \mathrm{H})$ & $(\mathrm{MW} / \mathrm{H})$ \\
\hline 1 & 0.0070 & 7.0 & 240 & 100 & 500 & 80 & 120 \\
\hline 2 & 0.0095 & 10.0 & 200 & 50 & 200 & 50 & 90 \\
\hline 3 & 0.0090 & 8.5 & 220 & 80 & 300 & 65 & 100 \\
\hline 4 & 0.0090 & 11.0 & 200 & 50 & 150 & 50 & 90 \\
\hline 5 & 0.0080 & 10.5 & 220 & 50 & 200 & 50 & 90 \\
\hline 6 & 0.0075 & 12 & 190 & 50 & 120 & 50 & 90 \\
\hline
\end{tabular}

Table 2: Load demand for 24 hours of six units system

\begin{tabular}{|c|c|c|c|c|c|c|c|}
\hline $\begin{array}{c}\text { Time } \\
(\mathrm{H})\end{array}$ & $\begin{array}{c}\text { Load } \\
(\mathrm{MW})\end{array}$ & $\begin{array}{c}\text { Time } \\
(\mathrm{H})\end{array}$ & $\begin{array}{c}\text { Load } \\
(\mathrm{MW})\end{array}$ & $\begin{array}{c}\text { Time } \\
(\mathrm{H})\end{array}$ & $\begin{array}{c}\text { Load } \\
(\mathrm{MW})\end{array}$ & $\begin{array}{c}\text { Time } \\
(\mathrm{H})\end{array}$ & $\begin{array}{c}\text { Load } \\
(\mathrm{MW})\end{array}$ \\
\hline 1 & 955 & 7 & 989 & 13 & 1190 & 19 & 1159 \\
\hline 2 & 942 & 8 & 1023 & 14 & 1251 & 20 & 1092 \\
\hline 3 & 9354 & 9 & 1126 & 15 & 1263 & 21 & 1023 \\
\hline 4 & 930 & 10 & 1150 & 16 & 1250 & 22 & 984 \\
\hline 5 & 935 & 11 & 1201 & 17 & 1221 & 23 & 975 \\
\hline 6 & 963 & 12 & 1235 & 18 & 1202 & 24 & 960 \\
\hline
\end{tabular}




$$
B i j=10^{-3}\left[\begin{array}{cccccc}
1.7 & 1.2 & 0.7 & -0.1 & -0.5 & -0.2 \\
1.2 & 1.4 & 0.9 & 0.1 & -0.6 & -0.1 \\
0.7 & 0.9 & 3.1 & 0.0 & -1.0 & -0.6 \\
-0.1 & 0.1 & 0.0 & 0.24 & -0.6 & -0.8 \\
-0.5 & -0.6 & -0.1 & -0.6 & 12.9 & -0.2 \\
-0.2 & -0.1 & -0.6 & -0.8 & -0.2 & 15.0
\end{array}\right]
$$

Table 3: Output powers, power losses and total fuel cost for 24 hours by Lambda iteration method of 6-units system

\begin{tabular}{|c|c|c|c|c|c|c|c|c|}
\hline Hour & $\begin{array}{c}\mathrm{P}_{1} \\
(\mathrm{MW})\end{array}$ & $\begin{array}{c}\mathrm{P}_{2} \\
(\mathrm{MW})\end{array}$ & $\begin{array}{c}\mathrm{P}_{3} \\
(\mathrm{MW})\end{array}$ & $\begin{array}{c}\mathrm{P}_{4} \\
(\mathrm{MW})\end{array}$ & $\begin{array}{c}\mathrm{P}_{5} \\
(\mathrm{MW})\end{array}$ & $\begin{array}{c}\mathrm{P}_{6} \\
(\mathrm{MW})\end{array}$ & $\begin{array}{l}\text { Loss } \\
(\mathrm{MW})\end{array}$ & $\begin{array}{l}\text { Fuel cost } \\
\qquad(\$)\end{array}$ \\
\hline 1 & 380.4615 & 123.3371 & 209.6713 & 86.0619 & 112.0658 & 50.0000 & 6.5454 & 11411.49 \\
\hline 2 & 377.2356 & 120.9510 & 207.2177 & 83.3767 & 109.5253 & 50.0000 & 6.3770 & 11247.53 \\
\hline 3 & 375.5586 & 119.7120 & 205.9428 & 81.9769 & 108.1951 & 50.0000 & 6.2903 & 11162.39 \\
\hline 4 & 374.2797 & 118.7655 & 204.9696 & 80.9146 & 107.1906 & 50.0000 & 6.2249 & 11097.72 \\
\hline 5 & 375.5586 & 119.7120 & 205.9428 & 81.9769 & 108.1951 & 50.0000 & 6.2903 & 11162.39 \\
\hline 6 & 382.4757 & 124.8263 & 211.2028 & 87.7407 & 113.6547 & 50.0000 & 6.6520 & 11514.21 \\
\hline 7 & 388.7815 & 129.4879 & 215.9959 & 93.0021 & 118.6308 & 50.0000 & 6.9922 & 11837.37 \\
\hline 8 & 396.2380 & 134.9471 & 221.5851 & 99.1484 & 124.3931 & 54.1809 & 7.3811 & 12271.75 \\
\hline 9 & 417.6234 & 150.5209 & 237.4881 & 116.7043 & 140.7398 & 71.6249 & 8.5625 & 13601.46 \\
\hline 10 & 422.5871 & 154.1345 & 241.1754 & 120.7834 & 144.5216 & 75.6584 & 8.8582 & 13914.01 \\
\hline 11 & 433.2687 & 161.9092 & 249.1052 & 129.5670 & 152.6439 & 84.3188 & 9.5220 & 14591.57 \\
\hline 12 & 440.2961 & 167.0206 & 254.3159 & 135.3508 & 157.9794 & 90.0073 & 9.9789 & 15041.12 \\
\hline 13 & 430.9261 & 160.2043 & 247.3667 & 127.6400 & 150.8645 & 82.4217 & 9.3732 & 14442.39 \\
\hline 14 & 443.6691 & 169.4772 & 256.8197 & 138.1265 & 160.5320 & 92.7258 & 10.2039 & 15257.84 \\
\hline 15 & 446.1478 & 171.2806 & 258.6574 & 140.1676 & 162.4089 & 94.7258 & 10.3716 & 15417.58 \\
\hline 16 & 443.4625 & 169.3269 & 256.6666 & 137.9565 & 160.3755 & 92.5590 & 10.1900 & 15244.54 \\
\hline 17 & 437.4019 & 164.9171 & 252.1718 & 132.9678 & 155.7812 & 87.6628 & 9.7888 & 14855.58 \\
\hline 18 & 433.4079 & 162.0080 & 249.2058 & 129.6825 & 152.7530 & 84.4367 & 9.5309 & 14600.51 \\
\hline 19 & 424.4496 & 155.4879 & 242.5559 & 122.3154 & 145.9427 & 77.1755 & 8.9713 & 14031.72 \\
\hline 20 & 410.5219 & 145.3478 & 232.2076 & 110.8721 & 135.3244 & 65.8493 & 8.1534 & 13156.92 \\
\hline 21 & 396.2380 & 134.9471 & 221.5851 & 99.1484 & 124.3931 & 54.1809 & 7.3811 & 12271.75 \\
\hline 22 & 387.5739 & 128.5950 & 215.0780 & 91.9947 & 117.6794 & 50.0000 & 6.9263 & $11775 . .33$ \\
\hline 23 & 385.4290 & 127.0100 & 213.4481 & 90.2030 & 115.9833 & 50.0000 & 6.8100 & 11665.24 \\
\hline 24 & 381.6678 & 124.2280 & 210.5879 & 87.0701 & 113.0232 & 50.0000 & 6.6092 & 11473.07 \\
\hline \multicolumn{8}{|c|}{ Total Generation Cost $(\$)$} & 313045.50 \\
\hline
\end{tabular}


Table 4: Output powers, power losses and total fuel cost for 24 hours by particle swarm optimization (PSO) of 6 units -system

\begin{tabular}{|c|c|c|c|c|c|c|c|c|}
\hline Hour & $\begin{array}{c}\mathrm{P}_{1} \\
(\mathrm{MW})\end{array}$ & $\begin{array}{c}\mathrm{P}_{2} \\
(\mathrm{MW})\end{array}$ & $\begin{array}{c}\mathrm{P}_{3} \\
(\mathrm{MW})\end{array}$ & $\begin{array}{c}\mathrm{P}_{4} \\
(\mathrm{MW})\end{array}$ & $\begin{array}{c}\mathrm{P}_{5} \\
(\mathrm{MW})\end{array}$ & $\begin{array}{c}\mathrm{P}_{6} \\
(\mathrm{MW})\end{array}$ & $\begin{array}{c}\text { Loss } \\
(\mathrm{MW})\end{array}$ & $\begin{array}{c}\text { Fuel cost } \\
\text { (\$) }\end{array}$ \\
\hline 1 & 381.5714 & 120.8702 & 210.4459 & 86.5109 & 112.1413 & 50.0000 & 6.5396 & 11410.86 \\
\hline 2 & 375.6001 & 118.3435 & 208.2801 & 84.9338 & 111.2008 & 50.0000 & 6.3583 & 11248.50 \\
\hline 3 & 372.1313 & 116.8757 & 207.0221 & 84.5696 & 110.6544 & 50.0000 & 6.2531 & 11161.44 \\
\hline 4 & 369.6539 & 115.8275 & 206.1235 & 84.3094 & 110.2642 & 50.0000 & 6.1785 & 11099.41 \\
\hline 5 & 372.1313 & 116.8757 & 207.0221 & 84.5696 & 110.6544 & 50.0000 & 6.2531 & 11161.44 \\
\hline 6 & 384.9939 & 122.2077 & 211.6352 & 87.7447 & 113.0670 & 50.0000 & 6.6485 & 11511.17 \\
\hline 7 & 394.9573 & 126.2967 & 215.8115 & 92.0565 & 116.8847 & 50.0000 & 7.0069 & 11838.94 \\
\hline 8 & 399.0251 & 133.7940 & 222.1091 & 96.2167 & 122.7501 & 56.4862 & 7.3813 & 12270.52 \\
\hline 9 & 420.7399 & 145.6516 & 239.2728 & 114.8466 & 140.7699 & 73.2912 & 8.5720 & 13599.88 \\
\hline 10 & 427.7292 & 148.1256 & 243.1505 & 118.8350 & 143.3025 & 77.7136 & 8.8569 & 13914.45 \\
\hline 11 & 443.1065 & 154.9287 & 247.8817 & 127.5496 & 151.0744 & 85.9687 & 9.5097 & 14588.85 \\
\hline 12 & 452.3793 & 160.5090 & 251.5363 & 133.1629 & 155.4444 & 91.9242 & 9.9565 & 15042.84 \\
\hline 13 & 439.1911 & 153.2747 & 246.5499 & 125.5640 & 150.2959 & 84.4946 & 9.3702 & 14442.65 \\
\hline 14 & 456.1396 & 162.7014 & 254.3155 & 136.3330 & 157.9999 & 93.6931 & 10.1835 & 15257.49 \\
\hline 15 & 458.8923 & 164.5063 & 255.7054 & 138.9330 & 159.2996 & 95.9928 & 10.3293 & 15419.10 \\
\hline 16 & 455.6563 & 162.5096 & 254.1511 & 136.2857 & 157.9286 & 93.6342 & 10.1662 & 15244.01 \\
\hline 17 & 447.6668 & 158.8386 & 250.4331 & 129.9988 & 153.7482 & 90.0963 & 9.7821 & 14855.29 \\
\hline 18 & 443.5074 & 155.0878 & 248.0181 & 127.6891 & 151.1336 & 86.0866 & 9.5234 & 14602.16 \\
\hline 19 & 430.7223 & 149.6136 & 244.1688 & 120.3298 & 144.2447 & 78.8929 & 8.9723 & 14032.85 \\
\hline 20 & 414.3692 & 141.9872 & 233.4176 & 109.2408 & 133.8613 & 67.2768 & 8.1531 & 13157.51 \\
\hline 21 & 399.0251 & 133.7940 & 222.1091 & 96.2167 & 122.7501 & 56.4862 & 7.3813 & 12270.52 \\
\hline 22 & 393.7541 & 125.3609 & 214.9522 & 90.9498 & 115.9247 & 50.000 & 6.9416 & 11775.78 \\
\hline 23 & 390.2814 & 124.3894 & 213.6910 & 89.0846 & 114.3769 & 50.0000 & 6.8235 & 11662.16 \\
\hline 24 & 383.5108 & 121.5776 & 211.0951 & 87.4883 & 112.9324 & 50.0000 & 6.6042 & 11473.52 \\
\hline \multicolumn{8}{|c|}{ Total Generation Cost $(\$)$} & 313041.40 \\
\hline
\end{tabular}




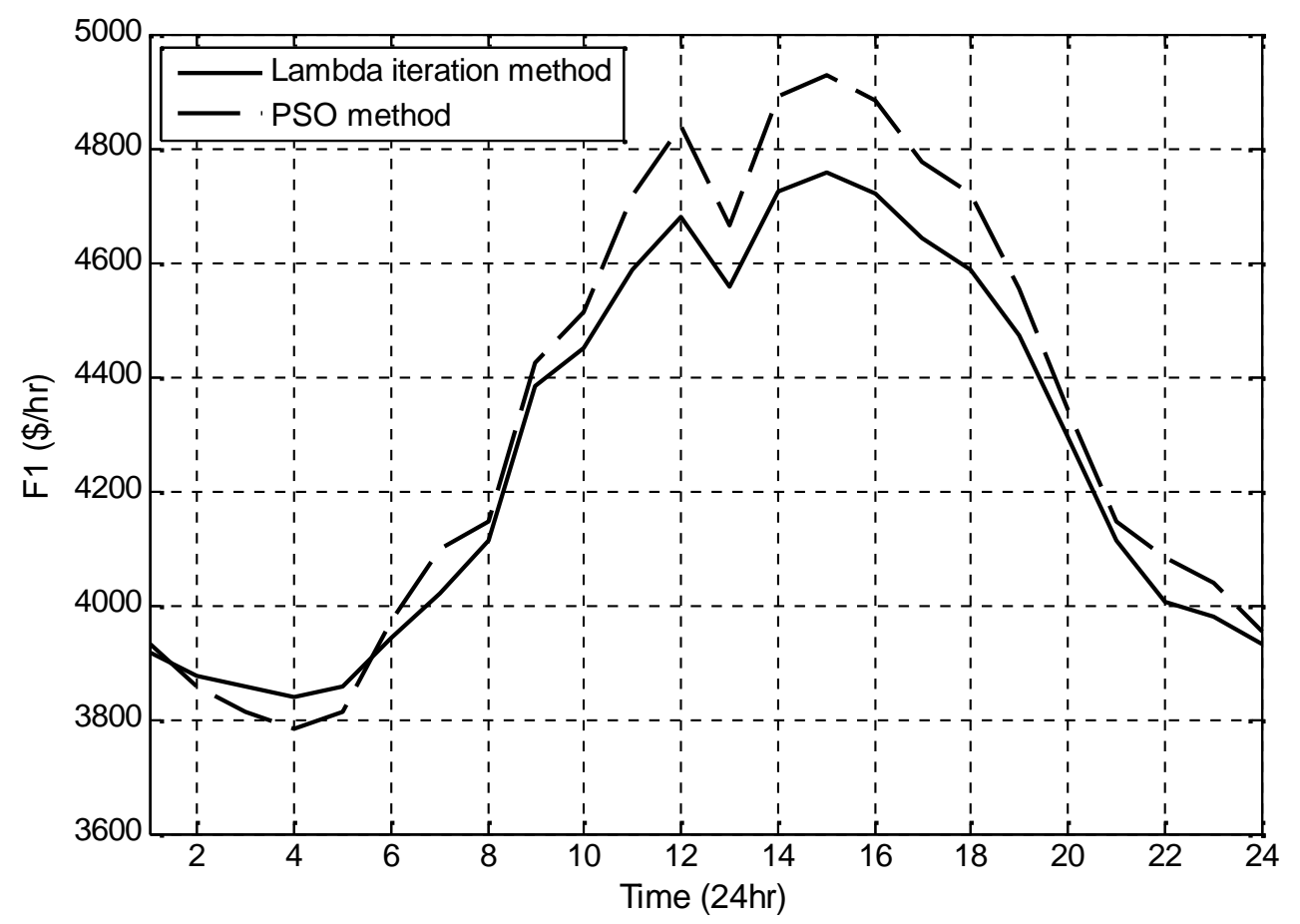

Fig.2. Fuel cost of unit 1 versus 24 hour by using two methods

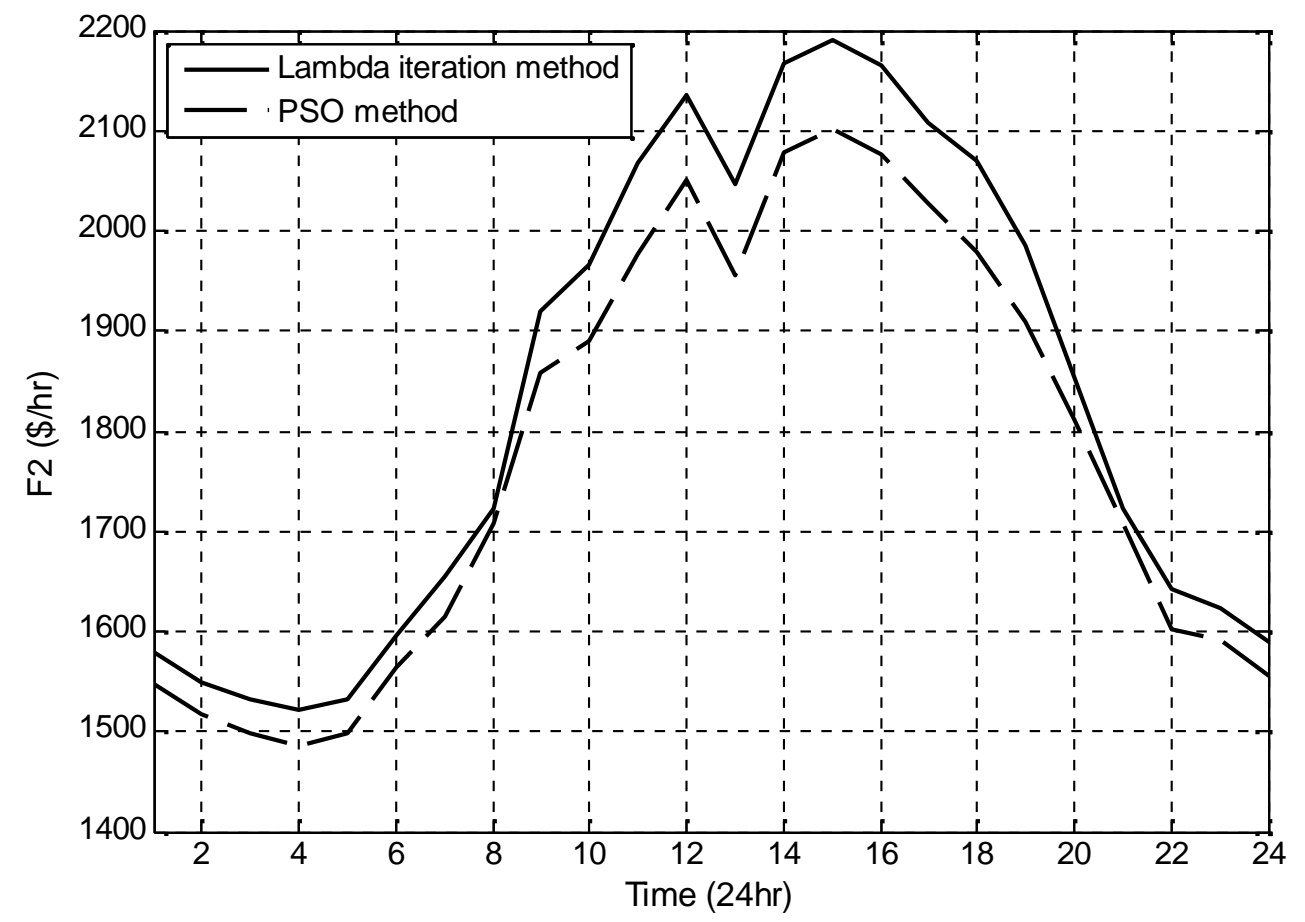

Fig.3. Fuel cost of unit 2 versus 24 hour by using two methods 


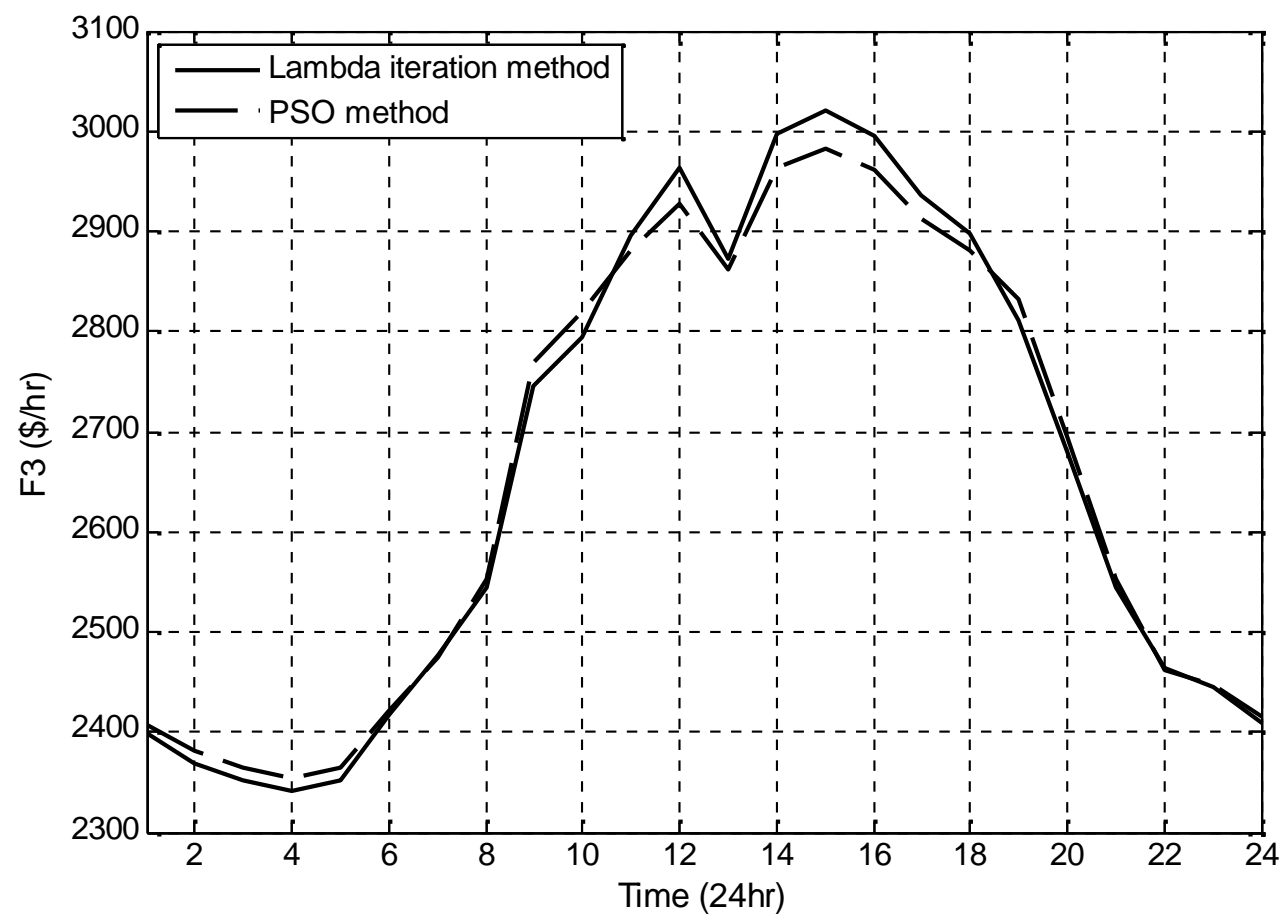

Fig.4. Fuel cost of unit 3 versus 24 hour by using two methods

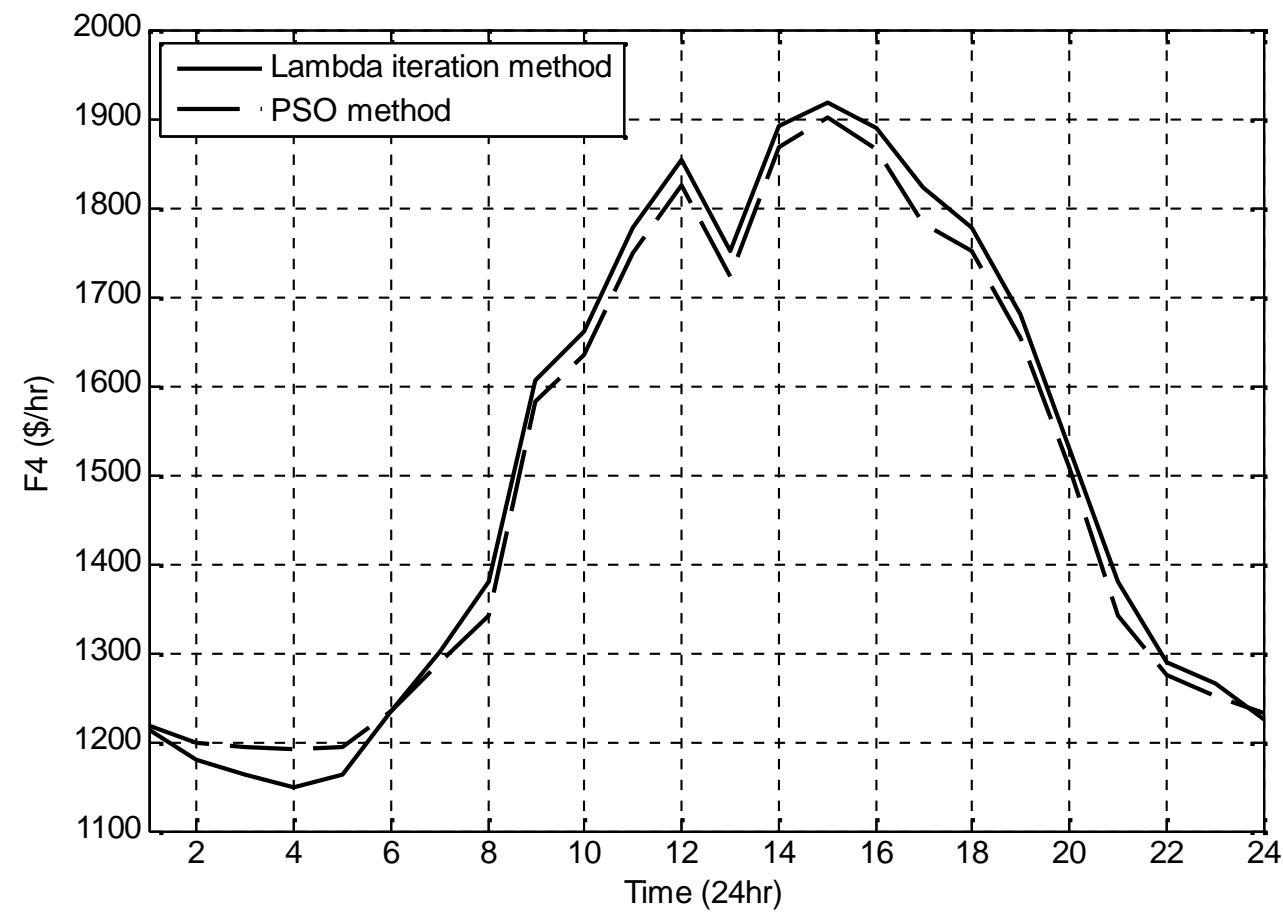

Fig.5. Fuel cost of unit 4 versus 24 hour by using two methods 


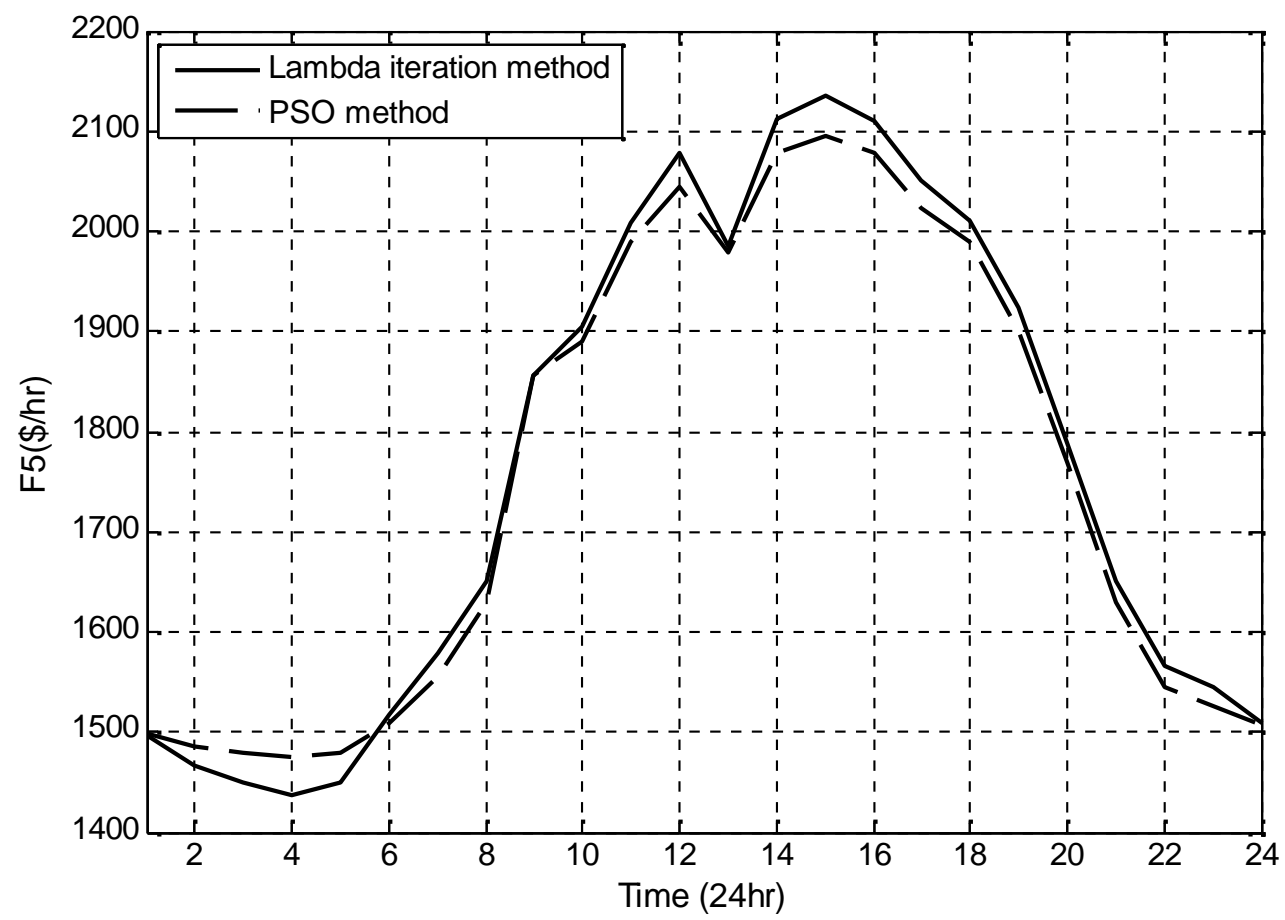

Fig.6. Fuel cost of unit 5 versus 24 hour by using two methods

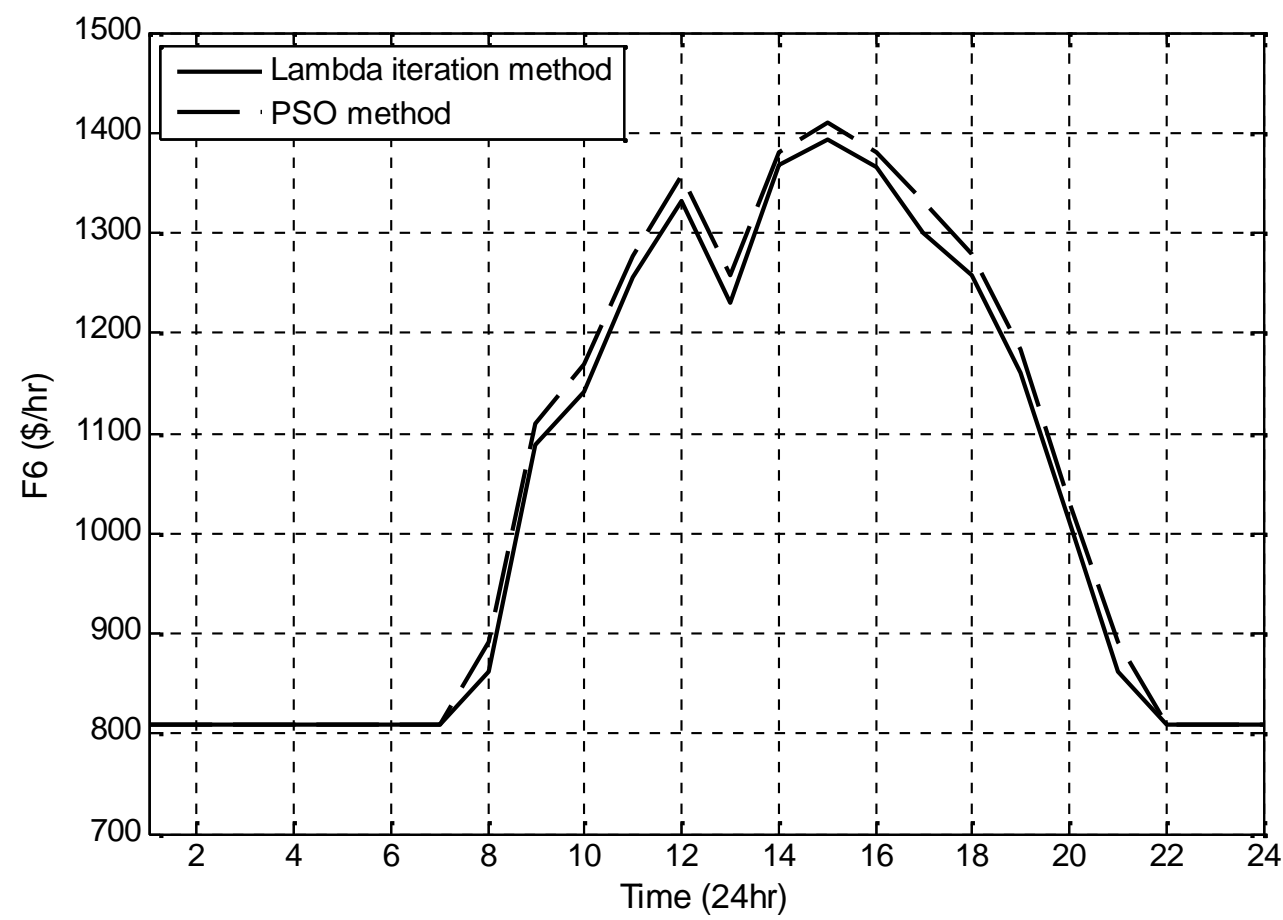

Fig.7. Fuel cost of unit 6 versus 24 hour by using two methods 


\section{Conclusions}

In this paper, particle swarm optimization (PSO) algorithm is used to solve the ELD problem. The proposed PSO algorithm has been successfully implemented for solving the ELD problem of a power system consists of 6 units with different constraints such as real power balance, generator power limits and ramp rate limits. The ELD problem includes the transmission line losses. From the tabulated results, it is clear that the PSO algorithm gives high quality solutions with fast convergence characteristic compared to the lambda iteration method. The PSO algorithm performs better than lambda iteration method in terms of the power loss. The lambda iteration method is also applicable, but it can converge to the minimum generation cost after so many iterations. So, the computational time of the lambda iteration method is much greater than the proposed PSO algorithm.

\section{References}

[1] A. J. Wood and B.F. Wollenberg, "Power Generation, Operation, and Control," John Wiley and Sons., New York (1984).

[2] Salama, M., M., "Economic control for generation in thermal power system", Energy Conversion and Management, 40, 1999, PP. 669-681.

[3] IEEE Committee Report, "Present practices in the economic operation of power systems", IEEE Trans. Power Appa. Syst., PAS-90 (1971) 1768-1775.

[4] N. Sinha, R. Chakrabarti and P.K. Chattopadhyay, "Evolutionary programming techniques for economic load dispatch", IEEE Evol. Comput., 7 (February (1)) (2003), PP. 83-94.

[5] K. P. Wong and C. C. Fung, "Simulated annealing based economic dispatch problem", IEEE Proc.-C, Vol. 140, No. 6, 1993, PP509-515.

[6] D.C. Walters and G.B. Sheble, "Genetic algorithm solution of economic dispatch with valve point loading", IEEE Trans. Power Syst., 8 (August(3)) (1993), PP. 1325-1332.

[7] J. Tippayachai, W. Ongsakul and I. Ngamroo, " Parallel micro genetic algorithm for constrained economic dispatch", IEEE Trans. Power Syst., 17 (August (3)) (2003), PP. 790-797.

[8] W.M. Lin, F.S. Cheng and M.T. Tsay, "An improved Tabu search for economic dispatch with multiple minima", IEEE Trans. Power Syst., 17 (February

(1)) (2002), PP. 108-112. 
[9] Y. Shi and R.C. Eberhart, "Empirical study particle swarm optimization", Proceedings of the 1999 Congress on Evolutionary Computation, PP. 1945-1950, 1999.

[10] Y. Shi and R.C. Eberhart, "Fuzzy adaptive particle swarm optimization", IEEE Int. Conf. Evol. Comput. (2001), PP. 101-106.

[11] Z.L. Gaing, "Constrained dynamic economic dispatch solution using particle swarm optimization", IEEE Power Engineering Society General Meeting, PP. 153-158, 2004.

[12] J.B. Park, K.S. Lee, J.R. Shin and K.Y. Lee, "A Particle swarm optimization for economic dispatch with non smooth cost functions", IEEE Trans . Power Syst,. 20 (February (1)) (2005), PP. 34-42.

[13] D.N. Jeyakumar, T. Jayabarathi and T. Raghunathan, "Particle swarm optimization for various types of economic dispatch problems", Elec. Power Energy Syst,. 28 (2006), PP. 36-42.

[14] J.A. Momoh, M.E. El-Hawary and R. Adapa, A review of selected optimal power flow literature to 1993, Part 1,"Non linear and quadratic programming approaches", IEEE Trans. Power Syst., 14 (1) (1999), PP. 96-104.

[15] Y. Shi and R.C. Eberhart, "Parameters selection in particle swarm optimization", Proceedings, of the Seventh Annual Conference on Evolutionary Programming, IEEE Press (1998).

[16] H. Saadat, Power System Analysis, McGraw-Hill, New York, 1999.

[17] H.T. Yang, P.C. Yang and C.L. Huang, "Evolutionary programming based economic dispatch for units with non smooth fuel cost functions", IEEE Trans. Power Syst., 11 (February (1)) (1996), PP.112-118.

[18] B. H. Chowdhury and S. Rahman, " A review of recent advances in economic dispatch", IEEE Trans. Power Syst, 5 (4) (1990), PP. 1248-1259. 